\title{
Evaluation of Excipient Risk in BCS Class I and III Biowaivers
}

\author{
Melissa Metry ${ }^{1}$ and James E. Polli, ${ }^{1,2}$
}

Received 7 October 2021; accepted 30 November 2021; published online 5January 2022

\begin{abstract}
The objective of this review article is to summarize literature data pertinent to potential excipient effects on intestinal drug permeability and transit. Despite the use of excipients in drug products for decades, considerable research efforts have been directed towards evaluating their potential effects on drug bioavailability. Potential excipient concerns stem from drug formulation changes (e.g., scale-up and post-approval changes, development of a new generic product). Regulatory agencies have established in vivo bioequivalence standards and, as a result, may waive the in vivo requirement, known as a biowaiver, for some oral products. Biowaiver acceptance criteria are based on the in vitro characterization of the drug substance and drug product using the Biopharmaceutics Classification System (BCS). Various regulatory guidance documents have been issued regarding BCS-based biowaivers, such that the current FDA guidance is more restrictive than prior guidance, specifically about excipient risk. In particular, sugar alcohols have been identified as potential absorption-modifying excipients. These biowaivers and excipient risks are discussed here.
\end{abstract}

KEY WORDS: bioavailability; bioequivalence; Biopharmaceutics Classification System (BCS); biowaiver; excipient.

\begin{tabular}{l}
\hline Guest Editors: Marilyn N. Martinez, Balint Sinko and Fang Wu \\
${ }^{1}$ Department of Pharmaceutical Sciences, School of Pharmacy, \\
University of Maryland, Baltimore, Maryland, USA. \\
${ }^{2}$ To whom correspondence should be addressed. (e-mail: \\
jpolli@rx.umaryland.edu)
\end{tabular}

Abbreviations: $A M E$, Absorption-modifying excipient; $A N D A, \mathrm{Ab}-$ breviated New Drug Application; $A O T$, Sodium 1,4-bis (2ethylhexoxy)-1,4-dioxobutane-2-sulfonate; $A P I$, Active drug ingredient; $A U C$, Area under the plasma-concentration time curve; $B C R P$, Breast cancer resistance protein; $B C S$, Biopharmaceutics Classification System; $B E$, Bioequivalence; Caco-2, Human colon adenocarcinoma cell line; $C A S$, Chemical abstracts service; $C_{\max }$, Maximum plasma concentration; $C T A B$, Cetyltrimethylammonium bromide; $E D T A$, Ethylenediamine tetraacetic acid; $E M A$, European Medicines Agency; FDA, Food and Drug Administration; FIP, International Pharmaceutical Federation; GI, Gastrointestinal; HEK293, Human embryonic kidney 293 cells; HPMC, Hypromellose; HT29, Human adenocarcinoma colorectal cell line; $I C H$, International Council for Harmonisation of Technical Requirements for Pharmaceuticals for Human Use; IID, Inactive Ingredient Database; IR, Immediate release; $M D C K$, Madin-Darby canine kidney; $M D E$, Maximum daily exposure; $M D R 1$, Multi-drug resistance mutation 1; MTX, Methotrexate; $N a C M C$, Sodium carboxymethylcellulose; $N D A$, New Drug Application; PEG, Polyethylene glycol; PEPT, Proton-coupled oligopeptide transporter; $P$-gp, P-glycoprotein; $P K$, Pharmacokinetic; $S L S$, Sodium lauryl sulfate; SNAC, Salcaprozate sodium; SUPAC, Scale-up and post-approval changes; $U N I$, Unique ingredient identifier; Vit-E-PEG, D- $\alpha$-tocopherol poly-(ethylene glycol) succinate; WHO, World Health Organization.

\section{INTRODUCTION}

Following oral administration, solid dosage formulations must first disintegrate in the gastrointestinal (GI) tract and dissolve in solution for drug absorption to occur. Based on the drug's physiochemical properties, intestinal permeation occurs by passive diffusion or active/facilitative transport (1). Of the fraction of the oral dose that is absorbed from the intestinal lumen, the fraction that becomes available in systemic circulation (i.e., is bioavailable) is further reduced by metabolism through the gut wall into the hepatic portal circulation, metabolism by first pass elimination through the liver, and biliary excretion (2).

Oral drug absorption is a process that is influenced by key biopharmaceutical and physiological factors. Important physiochemical properties of the drug include its solubility, intrinsic dissolution rate, ionization $\left(\mathrm{pK}_{\mathrm{a}}\right)$, lipophilicity (log P), stability, surface area, crystallinity, polymorphism, salt form, and molecular size. Physiological factors such as gastrointestinal $\mathrm{pH}$, gastric emptying, small intestinal transit time, bile salts, and mechanisms of membrane permeability also influence oral drug absorption (3). Non-drug components of the dosage formulation, i.e., excipients, may also impact absorption of the drug. Excipients are typically used in dosage formulations to ensure manufacturability and content uniformity but are also used to modulate drug substance or active drug ingredient (API) stability and bioavailability. 
Generally, excipients can potentially have an impact on drug absorption by altering the dosage formulation's disintegration, dissolution, or stability, or by directly impacting GI physiological processes.

It is well appreciated that excipients can alter drug release rate and/or extent of release from dosage formulations. However, there are several anticipated mechanisms through which excipients in the GI tract could impact drug absorption. For example, excipients may potentially modify GI transit time and luminal volumes, alter permeability, or modify metabolism within the GI tract (4). Osmotically active excipients such as sugar-alcohols (e.g., mannitol, sorbitol) and polyethylene glycol (PEG) 400 are known to potentially reduce drug absorption by increasing GI fluid volume, which in turn dilutes intraluminal drug concentration and reduces small intestinal transit time (5). However, other potential concerns such as excipient impact on drug membrane permeability have much less evidence of an effect in vivo (5-9).

Given the potential excipient risks to drug absorption, changes to drug formulations should consider excipient amount, mechanism(s) in which excipient may impact absorption, and the drug's absorption properties $(10,11)$. In vivo bioequivalence (BE) studies are generally needed to demonstrate a lack of impact of significant formulation changes on a drug's bioavailability during its development, for postapproval manufacturing changes, and when developing generic products. A regulatory framework to provide regulatory relief based on the in vitro characterization of the drug substance and drug product, termed Biopharmaceutics Classification System (BCS), allows the waiving of clinical BE studies for some immediate-release (IR) solid oral dosage formulations. Not needing human BE trials provides a great benefit in that it reduces drug development costs and eliminates unnecessary clinical trials (12). For various reasons, in vitro studies are sometimes better than conventional human pharmacokinetic in vivo studies in assessing BE of IR solid oral dosage formulations (13).

\section{BCS CLASSIFICATION AND BCS-BASED BIOWAIVERS}

The BCS classifies orally administered immediate release drug products based on the fundamental principles that control the rate and extent of drug absorption, i.e., solubility, dissolution rate, and intestinal permeability. The categories are high solubility-high permeability (Class I), low solubilityhigh permeability (Class II), high solubility-low permeability (Class III), and low solubility-low permeability (Class IV) (14).

The first finalized US Food and Drug Administration (FDA) BCS guidance for industry was issued in August 2000 and indicated that evidence of $\mathrm{BE}$ via in vitro dissolution studies in lieu of in vivo pharmacokinetic profiles may be sufficient for BCS Class I drugs. Such biowaivers were also supported by the European Medicines Agency (EMA) in their guidance issued in 2001. EMA and FDA expanded BCS-based biowaivers to include Class III drugs in 2010 and 2017, respectively $(15,16)$. Although the World Health Organization (WHO) considered granting BCS biowaivers for Class II weak acids, the organization published a guideline in 2015 for only Class I and Class III generic drugs (17).

The International Council for Harmonisation of Technical Requirements for Pharmaceuticals for Human Use (ICH), which involves experts from both regulatory and industry agencies, finalized a guideline intended to be recognized worldwide, entitled "M9 guideline on biopharmaceutics classification system-based biowaivers (Step 5)" in 2020 (10). With the support of ICH, FDA recently finalized a guidance for industry in May 2021 entitled "M9 Biopharmaceutics Classification System-Based Biowaivers," which replaced the 2017 FDA guidance (11). Relative to the 2017 FDA guidance, the 2021 FDA guidance (i.e., M9 document) has some biowaiver acceptance criteria changes, as summarized in Table I. Both documents indicate that BCS Class I and III drug products may be eligible for a biowaiver for IR oral dosage formulations with the same strength as the reference product. Acceptance criteria consist of the composition (i.e., excipients) and in vitro dissolution performance of the drug product depending on its BCS classification (11). It should be noted that M9 is a notable step forward, as it is the first harmonized allowance of BCS-based regulatory relief, including for example, in Japan.

However, M9 guidance is more restrictive than the prior 2017 FDA guidance, specifically about excipient risk. The 2017 FDA guidance indicated, in the context of BCS-based biowaivers, "In general, using excipients that are currently in FDA-approved IR solid oral dosage forms will not affect the rate or extent of absorption of a highly soluble and highly permeable drug substance that is formulated in a rapidly dissolving IR product." On the other hand, M9 lacks such a statement. The prior 2017 FDA guidance also indicates, "Unlike for BCS class 1 products, for a biowaiver to be scientifically justified, BCS class 3 test drug product must contain the same excipients as the reference product," and further describes evaluation of "the same excipients" (e.g., qualitatively the same and quantitatively similar). While the prior 2017 FDA guidance anticipates common excipients to not be a concern for BCS Class I, this expectation is less evident from the M9 guidance. M9 does indicate "[BCS Class I drugs] generally represent a low risk group of compounds in terms of the potential for excipients to affect absorption, compared to other BCS classes. Consideration of excipient effects for BCS Class I drug products should focus on potential changes in the rate or extent of absorption." However, this statement is only relative to other BCS classes and apparently does not convey the anticipation that common excipients are not a concern for BCS Class I drugs. An additional restriction is observed where Caco- 2 is indicated as the only in vitro permeability assessment in M9, while the prior guidance states in vitro permeability methods using excised intestinal tissues, or monolayers of suitable epithelial cells, may be used. This difference is a notable narrowing.

EMA and FDA have published product-specific guidances, and the International Pharmaceutical Federation (FIP) has published over 50 drug monographs that assess potential usage of BCS biowaivers (17). BCS-based biowaiver monographs are a series of literature reviews on IR solid oral dosage formulations published in the Journal of Pharmaceutical Sciences. Evaluation of the API's physiochemical properties, pharmacokinetics, and interactions with excipients are 
Table I. Comparison of 2017 FDA Versus 2021 M9 BCS-Based Biowaiver Criteria

\begin{tabular}{|c|c|c|}
\hline Criteria & 2017 FDA Guidance & 2021 M9 Guidance \\
\hline Dosage form & Solid oral dosage forms & Solid oral dosage forms or suspensions \\
\hline Drug substance & Must be the same & $\begin{array}{l}\text { Different salt form may be applicable (BCS Class I); } \\
\text { ester, ether, isomer, mixture of isomers, complex or } \\
\text { derivative are not applicable }\end{array}$ \\
\hline $\begin{array}{l}\text { Solubility class boundary } \\
\text { or drug amount }\end{array}$ & Highest strength & Highest single therapeutic dose \\
\hline Solubility assessment & $\begin{array}{l}\text { Ionization determines number of } \mathrm{pH} \text { conditions } \\
\text { within } 1-6.8 \text {, including } \mathrm{pH}=\mathrm{pKa} ; \mathrm{pH}=\mathrm{pKa}+1 ; \\
\mathrm{pH}=\mathrm{pKa}-1 \text {, and at } \mathrm{pH}=1 \text { and } 6.8\end{array}$ & $\begin{array}{l}\text { At least three pHs within } 1.2-6.8 \text {, including buffers } \\
\text { at } \mathrm{pH} 1.2,4.5 \text {, and } 6.8\end{array}$ \\
\hline Permeability assessment & $\begin{array}{l}\text { Preference for human PK studies } \\
\text { (e.g., absolute bioavailability or mass } \\
\text { balance); in vivo human intestinal } \\
\text { perfusion; animal in vivo or in situ } \\
\text { intestinal perfusion, excised } \\
\text { animal/human intestinal tissues, } \\
\text { or epithelial cell monolayers } \\
\text { possible for passively absorbed drugs, } \\
\text { although human data supersedes }\end{array}$ & $\begin{array}{l}\text { Preference for human PK studies (e.g., absolute } \\
\text { bioavailability or mass balance); Caco-2 permeability } \\
\text { is considered for passively absorbed drugs }\end{array}$ \\
\hline Excipients & $\begin{array}{l}\text { BCS Class I: Generally, excipients will } \\
\text { not affect rate or extent of absorption; } \\
\text { consider excessive quantities of } \\
\text { surfactants (e.g., polysorbate } 80 \text { ) and } \\
\text { sugar alcohols (e.g., mannitol or sorbitol) } \\
\text { BCS Class III: Excipients must be qualitatively } \\
\text { the same and quantitatively similar, except } \\
\text { for excipients used in limited amounts such } \\
\text { as the coating/shell }\end{array}$ & $\begin{array}{l}\text { BCS Class I: Excipients that may affect absorption } \\
\text { of the particular API are qualitatively the same and } \\
\text { quantitatively similar (i.e., within } \pm 10 \% \text { of the weight } \\
\text { of excipient in the reference product and a cumulative } \\
\text { difference within } \pm 10 \% \text { ); any qualitative and quantitative } \\
\text { differences are acceptable for all other excipients } \\
\text { BCS Class III: Excipients must be qualitatively the same } \\
\text { and quantitatively similar, except for excipients used in } \\
\text { limited amounts such as colorants/flavoring }\end{array}$ \\
\hline $\begin{array}{l}\text { In vitro dissolution } \\
\text { performance }\end{array}$ & $\begin{array}{l}\text { Demonstrate } f_{2} \text { similarity factor of } \geq 50 \text {; } \\
\text { not necessary if test and reference both } \\
\text { have very rapid properties }(\geq 85 \% \text { for the } \\
\text { average percent dissolved in } \leq 15 \mathrm{~min}) \\
\text { To allow the use of mean data for } f_{2}, \\
\text { the coefficient of variation should not be } \\
\text { more than } 20 \% \text { at the earlier time points } \\
\text { (e.g., } 15 \mathrm{~min}) \text {, and should not be more } \mathrm{t} \\
\text { han } 10 \% \text { at other time points }\end{array}$ & $\begin{array}{l}\text { BCS Class I: test and reference should both have, } \\
\text { - very rapid properties ( } \geq 85 \% \text { for the average percent } \\
\text { dissolved in } \leq 15 \mathrm{~min}) \text {, or } \\
\text { - rapid properties }(\geq 85 \% \text { for the average percent } \\
\text { dissolved in } \leq 30 \mathrm{~min}) \text { and } f_{2} \text { similarity factor of } \geq 50 \\
\text { If one product has rapid and the other has very } \\
\text { rapid characteristics, demonstrate } f_{2} \text { similarity } \\
\text { factor of } \geq 50 \\
\text { When the coefficient of variation is too high, } f_{2} \\
\text { calculation is considered inaccurate and a conclusion } \\
\text { on similarity in dissolution cannot be made } \\
B C S \text { Class III: test and reference should both produce } \\
\text { very rapid properties }(\geq 85 \% \text { for the average } \\
\text { percent dissolved in } \leq 15 \text { min) }\end{array}$ \\
\hline
\end{tabular}

considered for biowaiver risk-based analysis. Many of the monographs support biowaivers for specific drugs and their corresponding IR dosage formulations, such as metformin, sitagliptin, and moxifloxacin (18-20). Meanwhile, a smaller number of monographs suggest against biowaivers for specific drugs and their corresponding IR dosage formulations, such as carbamazepine (i.e., due to its narrow therapeutic index) (21).

It should be noted that when comparing $\mathrm{BE}$ in vitro test results to in vivo test results, in vivo $\mathrm{BE}$ studies can have type I (i.e., consumer risk/false positive) and type II (i.e., producer risk/false negative) errors. Hence, a reason for discordance between a BCS biowaiver conclusion and an in vivo $\mathrm{BE}$ conclusion is type II error in $C_{\max }$ from in vivo pharmacokinetic (PK) BE studies. Of the in vivo $\mathrm{BE}$ metrics for rate and extent, $C_{\max }$ is the more common reason for BE failure (2225). Limitations of $C_{\max }$ as a $\mathrm{BE}$ metric are well described
(26-29). In a retrospective study performed in Brazil, 12 of 115 studies of Class III drug products provided nonbioequivalent (i.e., non-BE, where confidence interval exceeds $80-125 \%$ range) result, with 5 of those being bioinequivalent (i.e., point estimate is outside the range of $80-125 \%$ ) (30). Specifically, among the 12 non-BE studies, 7 were due to only $C_{\max }, 4$ were due to both $C_{\max }$ and $\mathrm{AUC}_{0-t}$, and 1 was due to only $\mathrm{AUC}_{0-t}$. Of the 5 bioinequivalent studies, 4 were caused by only $C_{\max }$ and 1 was due to $C_{\max }$ and $\mathrm{AUC}_{0-t}$. Similarly, for Class I drug products, 22 out of 140 studies provided a non-BE result, with 8 of those being bioinequivalent. Of the 22 non-BE studies, 18 were due to only $C_{\max }$ while 4 were due to both $C_{\max }$ and $\mathrm{AUC}_{0-t}$. Of the 8 bioinequivalent results, 7 were due to only $C_{\max }$ while 1 was due to both $C_{\max }$ and $\mathrm{AUC}_{0-t}$. Thus, it is important to consider that in vivo bioinequivalence can be due to limitations of $C_{\max }$. 


\section{CLASSIFICATION OF BCS CLASS I AND III AND ELIGIBLITY FOR BIOWAIVER}

According to the current FDA guidance, to be considered highly soluble, the highest single therapeutic dose must be soluble in $250 \mathrm{~mL}$ or less of aqueous media in at least three $\mathrm{pHs}$ within the range of $1.2-6.8$ at $37 \pm 1^{\circ} \mathrm{C}$. To be considered highly permeable, the drug product must have human pharmacokinetic results with an absolute bioavailability of $\geq 85 \%$ or a urine recovery of $\geq 85 \%$ via mass balance with demonstrated GI stability. Other in vivo data such as drug recovery in feces or data obtained from the literature (e.g., product knowledge and bioavailability studies) may be acceptable. In vitro methods include Caco-2 cell permeability assays, but they should be used alongside available in vivo data to estimate intestinal drug absorption. If Caco-2 permeability assays are used alone to classify a drug as highly permeable, classification is limited to passively absorbed drugs due to the lack of certain intestinal transporters in the Caco-2 cell model (11).

Using comparative in vitro dissolution tests, the test and reference products of BCS Class I drugs must dissolve very rapidly ( $\geq 85 \%$ for the mean percent dissolved in $\leq 15 \mathrm{~min}$ ), or rapidly ( $\geq 85 \%$ for the mean percent dissolved in $\leq 30 \mathrm{~min}$ ) with similar $f_{2}(\geq 50)$ comparison. BCS Class III drugs must demonstrate very rapid comparative in vitro dissolution (11). Interestingly, the 2021 FDA Guidance does not allow for other methods to compare in vitro dissolution profiles other than $f_{2}$.

\section{POTENTIAL ABSORTION-MODIFYING EXCIPIENTS}

FDA's Inactive Ingredient Database (IID) catalogs all excipients used in approved New Drug Application (NDA) and Abbreviated New Drug Application (ANDA) products, regardless of current market availability of the drug product (31). Information on each excipient includes ingredient name, route of administration, dosage formulation, chemical abstracts service (CAS) number, unique ingredient identifier (UNII), maximum potency per unit dose, and maximum daily exposure (MDE).

Excipients are usually in much greater amounts than the API and can typically make up to $\sim 90 \%$ of the entire drug product. They are used in dosage forms to facilitate manufacturability, stability of the API, dose uniformity, and delivery of the API to the systemic circulation. Commonly used excipients can be grouped into several categories based on their functions such as binders (e.g., hypromellose, starch, povidone), fillers (e.g., lactose, mannitol), lubricants (e.g., magnesium stearate, stearic acid), and surfactants (e.g., sodium lauryl sulfate, polysorbates). Excipients are generally considered as "inactive ingredients." Some excipients (e.g., polymers) are utilized as enhancers of solubility or dissolution rate for poorly soluble drugs.

It can be conceived that absorption-modifying excipients (AMEs) that do not affect in vitro dissolution testing can be considered "critical" (i.e., concerning) for biowaivers since their effect on GI absorption (e.g., transit, intestinal permeability) would be overlooked. In the literature, only a subset of mechanisms exist by which excipients could function as AMEs and potentially affect the absorption of BCS Class III drugs. In contrast, BCS Class I drug absorption is not likely to be impacted by such excipients. For many potential AMEs, there is no in vivo evidence of such an effect. For example, we know of no common excipient that decreased drug absorption of a BCS Class I drug by drug-excipient binding where in vitro testing did not anticipate such binding. Many of the excipients with such reported effects, such as surfactants, would not normally be used in IR solid oral dosage forms for highly soluble drugs, i.e., BCS Class I and III. Only a few potential AMEs have been identified, such as excipients that can impact intestinal transit (e.g., sorbitol, mannitol). Evidence of an effect in humans for several of these AMEs has largely been observed with only high quantities of excipient (e.g., $1.6 \mathrm{~g}$ of sorbitol) (9). Although surfactants have also been associated as potentially critical AMEs, there is no clear evidence in humans. Rather, evidence has been observed in the preclinical and in vitro domains.

\section{Sorbitol and Mannitol}

The sugar alcohols sorbitol and mannitol are known to generate, in sufficient doses, significant osmotic effect after oral administration (i.e., decreases transit time that reduces drug absorption, particularly for low permeability drugs). The molecular weights of sorbitol and mannitol are the same (i.e., $182 \mathrm{Da}$ ), as they are stereoisomers, and they exhibit a dosedependent proportional decrease in small intestinal transit time (32,33). It is important to consider the amount of excipient used, the degree at which that amount affects BCS Class I or III drug absorption, and the absorption properties of the drug substance such as the location, rate, and mechanism $(4,11)$.

Chen et al. showed BCS Class III drugs were more sensitive than BCS Class I drugs to sorbitol, with respect to the ability of $5 \mathrm{~g}$ sorbitol to reduce drug absorption. Chen et al. employed metoprolol and ranitidine as Class I and Class III drugs, respectively. Test product containing $5 \mathrm{~g}$ of sorbitol had no impact on metoprolol extent of absorption compared to reference product containing sucrose in healthy volunteers. Meanwhile, ranitidine absorption was reduced by $7 \%, 25 \%$, and $45 \%$ by $1.25 \mathrm{~g}, 2.5 \mathrm{~g}$, and $5 \mathrm{~g}$ sorbitol, respectively (6). In general agreement with Chen et al.'s observation regarding metoprolol, Fassihi et al. observed that $10 \mathrm{~g}$ of sorbitol had no impact on the extent of theophylline, a BCS Class I drug $(7,8)$.

Vaithianathan et al. assessed commercial solutions containing sorbitol of each cimetidine and acyclovir, BCS Class III drugs, in bioequivalence studies (9). The cimetidine and acyclovir solutions contained about $1.6 \mathrm{~g}$ and $1.5 \mathrm{~g}$ of sorbitol, respectively. The dose containing $1.6 \mathrm{~g}$ sorbitol reduced cimetidine absorption by $19 \%$. Conversely, $1.5 \mathrm{~g}$ sorbitol did not impact acyclovir absorption. It is not clear why these similar doses of sorbitol showed apparently different impacts, although cimetidine and acyclovir are of course different drugs, including with different formulation compositions. Vaithianathan et al. also compared the cimetidine commercial solution (with about $1.6 \mathrm{~g}$ of sorbitol) against a sorbitol-free solution of cimetidine (9). While $C_{\max }$ was reduced by about $13 \%$, cimetidine absorption was not impacted. Overall results support Chen et al.'s observation that $1.25 \mathrm{~g}$ sorbitol can impact Class III drug absorption. An in silico model 
conducted by Yamane et al. estimated that a threshold of $400 \mathrm{mg}$ of sugar alcohols will not impact drug absorption (34).

Other studies examined quantities more than $2 \mathrm{~g}$ of sugar alcohols. Adkin et al. evaluated the impact of $2.264 \mathrm{~g}$ of mannitol on cimetidine absorption, as well as small intestinal transit times. Mannitol reduced cimetidine absorption by about $31 \%$, as well as small intestinal transit time by $23 \%$ (35). Also, Adkison et al. observed that 3.2, 10.2, and $13.4 \mathrm{~g}$ of sorbitol decreased absorption of lamivudine, a BCS Class III drug, by $20 \%, 39 \%$, and $44 \%$, respectively $(36,37)$.

\section{Surfactants}

Surfactant effect on permeability has been studied in vivo and in vitro, in regard to reducing small intestinal transit time or modifying passive or active permeation (4). However, in vivo human data has shown no effect.

The surfactant sodium lauryl sulfate (SLS) has been shown to increase permeability of mannitol and other drugs in Caco-2 monolayers via opening of tight junctions (38). SLS has also been classified as a modulator of paracellular transport from ex vivo data (39). Parr et al. showed SLS at $\geq 0.1 \mathrm{mg} / \mathrm{mL}$ increased permeability across Caco- 2 monolayers of four BCS Class III drugs due to damaging membrane integrity, but not the BCS Class I compound antipyrine. Concentrations of $0.01-0.04 \mathrm{mg} / \mathrm{mL}$ did not have any effect on the permeability of all five drugs (40). Although GarcíaArieta considered the in vivo impact of SLS where two studies showed bioinequivalence (with $3.64 \mathrm{mg}$ or $1.5 \mathrm{mg}$ SLS), other studies with very high amounts (9 g) have demonstrated bioequivalence (5). Vaithianathan et al. found that sodium lauryl sulfate $(25 \mathrm{mg}$ ) had no significant impact on the in vivo bioavailabilities of cimetidine nor acyclovir (9).

The surfactants Vit-E-PEG, AOT, polysorbate 80, CTAB, polysorbate 20, Cremophor ${ }^{\circledR}$ EL, Solutol ${ }^{\circledR}$ HS 15 , and $\mathrm{Brij}{ }^{\circledR} 58$ and the polymer $\mathrm{NaCMC}$ have been shown to be inhibitors of P-glycoprotein (P-gp) in MDCK-MDR1 cell culture, as determined by significant intracellular increase in digoxin (41). In an in vivo rat experiment, surfactants modified the pharmacokinetic profile of orally administered digoxin and celiprolol (BCS Class III), although the overall AUC was not increased. An early peak of absorption was observed consistently across surfactants, most likely due to the higher concentration of excipient in the proximal intestine where P-gp expression is lower (42).

\section{REGULATORY FRAMEWORK IN FORMULATION}

Biowaivers are allowed for scale-up and post-approval changes (SUPAC) to drug formulations. The FDA guidance on "Immediate Release Solid Oral Dosage Forms Scale-Up and PostApproval Changes" (SUPAC-IR) published in November 1995 outlines post-approval changes in the composition of formulation, manufacturing location, batch size, and manufacturing equipment and process. SUPAC-IR provides regulatory relief in the context of BCS. Specifically, excipient changes are divided into three impact levels on formulation quality and performance that are accepted by dissolution and in vivo BE requirements. The categories include level 1 (negligible impact), level 2 (could have a significant impact), and level 3 (likely to have a significant impact) (43).
Changes in excipients at level 1 are unlikely to affect the quality or performance of the formulation such as in the color or flavor of the drug product or excipient amounts less than or equal to a percentage $(\mathrm{w} / \mathrm{w})$ of the total formulation. Specifically, $\pm 5 \%$ for fillers, $\pm 3 \%$ for the disintegrant starch and $\pm 1 \%$ for other disintegrants, $\pm 0.5 \%$ for binders, $\pm 0.25 \%$ for the lubricants calcium or magnesium stearate or $\pm 1 \%$ for other lubricants, $\pm 1 \%$ for talc and $\pm 0.1 \%$ for other glidants, and $\pm 1 \%$ for film coating. Additionally, the total additive excipient changes must not be $>5 \%$. BE is demonstrated in level 1 via in vitro dissolution testing (i.e., biowaiver) (43).

Changes in excipients at level 2 could significantly alter the quality or performance of the formulation. Examples include a change in the technical grade of an excipient or in the percent $(\mathrm{w} / \mathrm{w})$ of the total formulation greater than level 1 but less than or equal to a two-fold increase over level 1 changes. Additionally, the total additive excipient changes must not be $>10 \%$. BE for level 2 is demonstrated via dissolution profile similarity factor $f_{2}$ (i.e., biowaiver) for BCS Class I, II, and III, with an exemption for BCS Class I drugs that show $\geq 85 \%$ dissolution in $900 \mathrm{~mL} 0.1 \mathrm{~N} \mathrm{HCl}$ in $15 \mathrm{~min}^{43}$

Changes in excipients at level 3 significantly alter the quality or performance of the formulation due to additive excipient changes of $>10 \%$ and require in vivo BE testing for qualification $(43,44)$.

FDA expanded its SUPAC-IR requirements in the guidance for ANDAs, in which excipient changes must be "Q1/Q2," i.e., the test formulation must be the same excipients (qualitatively the same; Q1) and in the same concentration (quantitively the same; Q2) to the reference formulation (45). Allowable qualitative excipient differences to be Q1 include those that affect the color or flavor of the drug product, printing ink, technical grade and/or specification, and particle size. Allowable quantifiable excipient differences to be Q2 include excipient amounts less than or equal to a percentage $(\mathrm{w} / \mathrm{w})$ of the total formulation. Specifically, the guidance for ANDAs states $\leq 10 \%$ for fillers, $\leq 6 \%$ for starch and $\leq 2 \%$ for other disintegrants, $\leq 3 \%$ for binders, $\leq 0.5 \%$ for the lubricants calcium or magnesium stearate or $\leq 2 \%$ for other lubricants, $\leq 2 \%$ for the glidant talc or $\leq 0.2 \%$ for other glidants, and $\leq 2 \%$ for film coating. Additionally, the total additive excipient changes must be $\leq 10 \%$ (45).

\section{EXCIPIENT RISK FOR BCS CLASS I}

BCS Class I drug products have minimal risk regarding excipient changes since they are very well absorbed given their high solubility and high permeability characteristics. Since the rate-determining steps are dissolution, permeation, or gastric emptying, excipients that could alter the rate or extent of the drug's absorption should still be evaluated. Such cases include excipients that modulate uptake transporters that the drug relies on for its high permeability, or excipients that increase the absorption rate of drugs that are absorbed slowly. A biowaiver is acceptable for BCS Class I drugs if the excipients that may affect absorption are qualitatively the same (i.e., identical chemistry, grade, and characterization) and quantitatively similar (i.e., within $\pm 10 \%$ of the weight of excipient in the reference product and a cumulative difference within $\pm 10 \%$ ). For all other excipients, any qualitative and quantitative differences in excipients are acceptable when granting a biowaiver $(10,11)$. 
Cephalexin, a BCS Class I drug, has high intestinal permeability due to active uptake across the apical membrane of enterocytes via the proton-coupled oligopeptide transporter PEPT1. Variations in the expression of PEPT1 in vitro and in vivo (i.e., Caco-2 cells, human duodenum, and rat jejunum) are correlated with differences in the permeability of cephalexin (46). Hypothetically, excipients that have the potential to modulate PEPT1 activity or expression could affect the extent of absorption of cephalexin and would be important to consider during formulation development. In general, a $10-15 \%$ change in extent of absorption can be expected to cause bioinequivalence (47).

In vitro data has shown the non-ionic surfactants Solutol ${ }^{\circledR}$ HS15 (poly-oxyethylene esters of 12-hydroxystearic acid), polysorbate 20, and polysorbate 80 inhibit PEPT1 in transfected MDCKII cells (48). Notably, surfactants are also known to enhance the penetration of drugs through the intestinal membrane by disrupting its integrity and function. Therefore, it is important to consider an overall net effect since multiple mechanisms may (or may not) be at play when surfactants are present in the GI tract (49). Similarly, in vitro and in situ experiments have shown the excipient caprylocaproyl macrogolglycerides to enhance cephalexin transport. However, these experiments fail to emulate the in vivo human environment that includes active transport and fail to consider an already high permeability of cephalexin (46).

\section{EXCIPIENT RISK FOR BCS CLASS III}

BCS Class III drug products are thought to be at risk of excipient changes since they have low permeability and may only be locally absorbed at specific sites along the gastrointestinal tract (e.g., only small intestine as colonic permeability is too low). Therefore, according to the current FDA guidance, a biowaiver is acceptable for BCS Class III drugs if all excipients are qualitatively the same (i.e., identical chemistry, grade, and characterization) and quantitatively similar (i.e., within $\pm 10 \%$ of the weight of excipient in the reference product and a cumulative difference within $\pm 10 \%$ ), except for excipients that are used in limited amounts such as the film coating or capsule shell. This criterion assumes that all excipients have the potential to affect absorption of the drug, regardless of known or suspected capability $(10,11)$.

Osmotically active excipients at amounts used in formulations have been shown to alter the bioavailability of BCS Class III drugs (50). Sorbitol decreased ranitidine absorption by increasing intestinal fluid volume, and thus enhancing GI motility and decreasing ranitidine transit time. Mannitol decreased the bioavailability of cimetidine. PEG 400 accelerated transit time and altered the absorption of ranitidine (50).

Valacyclovir, a BCS Class III drug and prodrug of acyclovir, is more permeable than administration as the parent drug acyclovir due to active uptake of valacyclovir (but not acyclovir) via PEPT1 such that bioavailability is improved to $>50 \%$ compared to $15 \%(9,51,52)$. Non-ionic surfactants have been shown in vitro to inhibit intestinal transporters, including via modulation of membrane fluidity (53-55). For example, polysorbate 80 has been shown to inhibit the intestinal transporter PEPT1 (48). Hypothetically, the PEPT1 substrate valacyclovir could be impacted by polysorbate 80 , which may potentially decrease valacyclovir absorption, although FDA M9 regulatory guidelines do not describe methods to assess transportermediated excipient-drug interactions.

If inhibition of intestinal efflux transporters affects permeability, there could be a potential increase in bioavailability, although not concerning for passive permeability drugs. Cimetidine and famotidine, which are both BCS Class III drugs, are substrates for intestinal efflux mediated by P-gp. Concentration-dependent decrease of the secretion of both drugs in situ via single-pass intestinal perfusion studies in rats was obtained by P-gp inhibitors. Notably, the in vivo permeability of both drugs along the small intestine correlated with P-gp expression levels, thereby exhibiting segmental dependent intestinal absorption. Site-specific P-gp inhibition along the intestine, as observed by verapamil in the literature, may impact overall drug absorption (56). Many surfactants and one polymer have also been shown in vitro to inhibit P-gp in MDCK-MDR1 cells while five dyes and one suspending agent showed minimal inhibition in HEK293 cells $(41,57)$.

The surfactant vitamin E TPGS (d- $\alpha$-tocopheryl polyethylene glycol 1000 succinate) has been classified as an inhibitor of P-gp-mediated drug transport in Caco-2 monolayers and other cell lines $(58,59)$. It has also been shown to enhance the oral bioavailability of the BCS Class III drug colchicine in rats (60). Notably, in vitro findings involving intestinal absorption of P-gp substrates have been performed using Caco-2 monolayers, although these cells have variable P-gp expression based on the culture conditions (61) and it is indicated that they overexpress P-gp (62).

Rege et al. assessed the influence of nine excipients (lactose, SLS, polysorbate 80, HPMC, docusate sodium, EDTA, propylene glycol, PEG 400, and anhydrous cherry flavor) on the Caco-2 permeability of seven low permeability compounds. Polysorbate 80 significantly increased apical-tobasolateral permeability of low permeability compounds via inhibition of active efflux as assessed by the lack of effect on mannitol permeability. SLS moderately increased drug permeability and affected Caco-2 monolayer integrity. The rest of the excipients showed minimal impact on the overall permeability of these compounds (54).

The surfactants salcaprozate sodium (SNAC) and sodium caprate $\left(\mathrm{C}_{10}\right)$ are two of the most advanced AMEs that have gone through clinical testing for the oral delivery of macromolecules. Oral semaglutide, which has gone through multiple phase 3 clinical trials, is the first oral peptide therapeutic for type 2 diabetes in the form of a daily capsule. It is thought that SNAC promotes semaglutide absorption in the stomach by raising local $\mathrm{pH}$ to protect drug from degradation by gastric enzymes, as well as by inducing transcellular flux of semaglutide across the gastric epithelium of the stomach. $\mathrm{C}_{10}$ was assessed for use with oral insulin although dosage formulation development was discontinued. Low concentrations of $\mathrm{C}_{10}$ act via openings of tight junctions, while high concentrations via membrane perturbation (63).

\section{DISCUSSION}

\section{Suitability of Experimental Models to Assess Drug Absorption}

Intestinal absorption is often determined using in situ rat perfusion models or in vitro epithelial cell culture models. It is 
important to consider the utility of these alternative methods to drug absorption in humans. In situ rat perfusion models exhibit physiological differences from humans such as dilution, gastric emptying, degradation, and intestinal transit. However, this model favorably assesses drug transport in small intestinal tissue, the main in vivo absorption site. Notably, although rat and human tissue show similar drug absorption profiles, they exhibit distinct transporter and metabolic enzyme expression in the intestinal wall. Therefore, a rat model can be used to predict oral drug absorption in the small intestine of human, but not to predict oral bioavailability (64).

Caco-2 cell monolayers are a sensitive tool capable of distinguishing between high and low permeability values. However, they present practical limitations as an in vitro model to assess excipient effects on drug permeability. For example, a theoretical increase in drug intestinal permeability of a Class III drug by a theoretical absorption-modifying excipient from $60 \%$ absorption to $65 \%$ may or may not be detectable by Caco-2 monolayers, or by in vivo human bioequivalence testing. Since the Caco-2 permeability assay has an intraday variability of $\sim 10 \%$ that is comparable to the bioequivalence similarity assessment (e.g., 10-15\%), it would be difficult to reliably detect small excipient effects for low permeability drugs by Caco- 2 monolayers. That is, a true enhancement of drug permeability of $10 \%$ across Caco- 2 monolayers may not reliably be detected, even though a $10 \%$ increase in in vivo drug absorption may be important. In general, a $10-15 \%$ change in extent of absorption can be expected to cause bioinequivalence (47).

However, in spite of a lower limit of sensitivity of Caco-2 monolayers to drug permeability enhancement, in the literature, Caco-2 cells have been highly sensitive to excipient effects on drug permeability compared to in vivo (54). Consistent with the sensitivity of Caco-2 monolayers, excipients such as surfactants, disintegrants, and chitosans have shown an effect on drug permeability across Caco-2 monolayers but not in vivo. Caco-2 monolayers can be expected to frequently over-predict in vivo effect of excipients, such as SLS. This over-prediction is in part because Caco-2 monolayers do not secrete mucus, such that Caco-2 is much more sensitive to membrane disruptors (i.e., surfactants) than in vivo. Mucus creates a steric and interactive barrier against intestinal permeation such that its presence (or absence) may impact drug permeation (65). Therefore, the in vivo implication of an enhancement in in vitro Caco-2 permeability by an excipient is not clear.

A practically challenging topic is the comparison of permeability values (e.g., with and without excipient). There is currently no known universal method to assess permeability similarity when employing an in vitro model such as Caco2 in assessing potential excipient effect. Although intraday variability in Caco-2 permeability is low, there is appreciable variability between studies (even conducted on the same day) that is often unexplained. This may lead statistical analysis via $t$-tests to false-positives, even before considering the high sensitivity of Caco-2 to predict in vivo human permeability. For example, Rege at al. reported a false-positive outcome in about $10 \%$ of all studies (54). These apparent effects were about 1.3-fold in magnitude, were not systematic, and attributed to variability effects than true excipients effects. Two studies were repeated and showed no subsequent excipient effect. In another two studies, "tighter" monolayers, as assessed by mannitol permeability, explained the decreased drug permeability. Parr et al. examined excipient effects on BCS Class III permeability using Caco- 2 monolayers and rat perfusion (40). It was concluded that the four BCS Class III compounds would not be greatly impacted by the excipients. Permeability values were examined in the presence and absence of excipient, but no statistical tests were conducted. It would appear that permeability comparisons should not be limited to straight-forward $t$-tests (either with or without multiple comparisons correction).

Madin-Darby canine kidney (MDCK) cells have also been used in permeability assays since they favorably grow more rapidly than Caco-2 cells. In drug discovery/ development interface programs that examine drug biopharmaceutic properties, MDCK monolayers are perhaps even more commonly used than Caco- 2 monolayers. MDCK and Caco-2 cells both form into polarized epithelial monolayers. Although Caco-2 and MDCK cells differ biological in their source (human colon and canine kidney, respectively), their monolayers have comparable apparent permeability coefficient values. Notably, they each differ and vary in their own transporter expression levels (66-68).

Other cell culture models may be a more practical permeability model worth further evaluation, such as human colon carcinoma cell lines HT29-H and HT29-MTX, which form a monolayer with a mucosal barrier $(69,70)$. Co-culture models of enterocyte-like Caco-2 cells with mucus-producing HT29-MTX cells have also been assessed for correlation with human in vivo studies, although relevant intestinal transporters are still not expressed (71-73). Bioengineering approaches that involve 3D co-cultures have also been reported in the literature as biomimetic models (74). Nonetheless, there is a need for novel in vitro models alongside the use of human and animal in vivo techniques to assess permeability (75).

\section{Considerations of Excipient-Transporter Interaction}

M9 guidance requires a BCS-based biowaiver proposal to include a mechanistic and risk-based approach in assessing if differences between test and reference product (e.g. pre- and post-change SUPAC products, brand versus proposed generic) will not affect drug absorption. One such potential mechanism is transporter-mediated drug absorption. Although M9 guidance references important intestinal transporters, i.e., P-gp and BCRP, Caco-2 cell monolayers are limited in M9 to only assessing high permeability of passively transported drugs due to the potential lack of transporter expression. Transporter-mediated risk assessment of excipients is discussed. A critical question is "Are there excipients in the formulation with known or suspected effects on drug absorption?"

Regarding the potential for transporter-mediated excipient-drug interactions, two other FDA guidances are more comprehensive in assessing such risks than M9: "In Vitro Drug Interaction Studies - Cytochrome P450 Enzyme- and Transporter-Mediated Drug Interactions" and "Clinical Drug Interaction Studies - Cytochrome P450 Enzyme- and Transporter-Mediated Drug Interactions." (76,77) These companion guidances are largely aimed at drug development in anticipating or assessing drug-drug interactions. The guidances are additionally supported with a website concerning tables that list substrates, inhibitors, and inducers of P450 
enzymes and transporters (78). Nine transporters are discussed, including two apically localized efflux transporters that have significant expression in the intestine: P-gp and breast cancer resistance protein (BCRP). Given their location and directionality of transport, they have the potential to translocate drug back into the gut lumen and reduce drug absorption. Correspondingly, for a drug that is incompletely absorbed due to such efflux, an excipient that inhibits P-gp and/or BCRP has the potential to increase drug absorption. In vitro dissolution would presumably not detect such an excipient effect.

The quality of experimental tools to evaluate transportermediated drug interactions varies and depends upon the question to be addressed. There are in vitro assays that are viewed as reliable to demonstrate that a drug, or presumably an excipient, is not an inhibitor (76). For example, vitamin E TPGS was shown to not inhibit human PEPT1 (55).

Meanwhile, in vitro assays showed the BCS Class III drug cimetidine to be a P-gp substrate and inhibitor $(9,79,80)$. This situation exemplifies the general challenge in addressing the question about whether or not excipients in a formulation have potential effects on drug absorption. It is well appreciated that, even for perpetrator drug substances much less perpetrator excipients, that in vitro tools to predict in vivo transporter impact or transporter-mediated drug interactions have limitations. These limitations include relevance of in vitro studies to in vivo impact, as well as specificity to one transporter over another transporter, as transporters such as P-gp and BCRP can have overlapping activities. Of note, M9 guidance lists four model drugs for permeability assay method validation: digoxin, paclitaxel, quinidine, and vinblastine. Of these, only digoxin and quinidine are listed as example probes in the FDA clinical drug-drug interaction guidance (77). This lack of convergence reflects that in vitro and in vivo tools, as well as overall understanding about transportermediated interactions at the level of the gut, are still often only modestly developed.

Such limitations are highlighted in examining the current, state-of-the-art recommendations for conducting in vivo clinical studies to assess transporter-mediated drug interactions, even for perpetrator excipients (77). This guidance notes clinical substrates of P-gp to include dabigatran etexilate, digoxin, and fexofenadine. The guidance further notes that criteria for selecting P-gp clinical substrates are (a) AUC foldincrease $\geq 2$ with verapamil or quinidine co-administration and (b) in vitro transport by P-gp expression systems, but not extensively metabolized. More importantly for one with an interest in assessing excipient risk to modulate P-gp (e.g., risk of excipient to increase drug absorption via $\mathrm{P}$-gp inhibition), the guidance notes that criteria for selecting P-gp clinical inhibitor are (a) AUC fold-increase of digoxin $\geq 2$ with coadministration and (b) in vitro inhibitor. That is, it is clear that digoxin is the state-of-the-art in vivo victim drug to assess a $\mathrm{P}$ gp-mediated drug interaction by a potential perpetrator drug (or excipient). Trueck et al. employed digoxin as the P-gp probe in a five-drug cocktail that aims to serve as a clinical tool to screen for transporter-based interactions (81).

However, there are specificity and sensitivity limitations in using digoxin as the P-gp probe for in vivo clinical studies (82). Oral absorption of digoxin from tablets is $60-80 \%$ (83), reflecting its intestinal permeability is less than high (84). However, with only $20-40 \%$ incomplete permeation due to perhaps P-gp, there is a modest amount that P-gp inhibition can increase digoxin absorption. Fexofenadine and dabigatran etexilate have been suggested to be more appropriate P-gp probes than digoxin to assess intestinal P-gp inhibition, although they also have significant limitations (85). Limitations in the availability of a suitable Pgp probe for in vivo clinical studies generally reflect the experimental challenges in assessing whether or not excipients in a formulation have potential in vivo effects on drug absorption. In other words, transporter effects are difficult to demonstrate or characterize, particularly in vivo.

Future research should be aimed to help better answer the critical question - "Are there excipients in the formulation with known or suspected effects on drug absorption?" Currently, in vitro and in vivo tools as well our overall understanding about transporter-mediated interactions at the level of the gut are often only modestly developed, making this critical question difficult to fully address. This difficulty is further challenged if there is the presumption of an excipient effect, which M9 appears to assume for even BCS Class I drugs.

\section{CONCLUSION}

Excipients affecting GI drug absorption limit the granting of BCS-based biowaivers. Excipients may impact small intestinal transit, passive permeability, or active transport for BCS Class III drugs. BCS Class I drugs are not likely to be impacted by common excipients. However, experience to date supports that common excipients in solid oral IR dosage formulations generally do not modify in vivo drug permeability or transit. A few potentially critical absorptionmodifying excipients have been identified at high quantities in vitro and preclinically, including excipients that can impact intestinal transit (e.g., sorbitol, mannitol). Nonetheless, the current FDA M9 guideline has conservative limits for excipient changes. These restrictions, especially for that of BCS Class III drugs, merit regulatory relief. A database of failed $\mathrm{BE}$ clinical trials because of excipient changes could help identify disallowable excipient changes to dosage formulations due to impacting performance.

\section{AUTHOR CONTRIBUTION}

Both authors contributed to the writing and approval of the version to be published.

\section{DECLARATIONS}

Conflict of Interest The authors declare no competing interests.

Open Access This article is licensed under a Creative Commons Attribution 4.0 International License, which permits use, sharing, adaptation, distribution and reproduction in any medium or format, as long as you give appropriate credit to the original author(s) and the source, provide a link to the Creative Commons licence, and indicate if changes were made. The images or other third party material in this article are included in the article's Creative Commons licence, unless indicated otherwise in a credit line to the material. If material is not included in the article's Creative Commons licence and your intended use is not permitted by statutory regulation or 
exceeds the permitted use, you will need to obtain permission directly from the copyright holder. To view a copy of this licence, visit http://creativecommons.org/licenses/by/4.0/.

\section{REFERENCES}

1. El-Kattan A, Varm M. Oral absorption, intestinal metabolism and human oral bioavailability. In: Paxton J, editor. Topics on Drug Metabolism. Croatia: InTech; 2012. p. 1-34.

2. Sugano K. Biopharmaceutics modeling and simulations: theory, practice, methods, and applications. New Jersey: Wiley, 2012.

3. Panakanti R, Narang AS. Impact of excipient interactions on drug bioavailability from solid dosage forms. Pharm Res. 2012;29(10):2639-59. https://doi.org/10.1007/s11095-012-0767-8.

4. Flanagan T. Potential for pharmaceutical excipients to impact absorption: a mechanistic review for BCS Class 1 and 3 drugs. Eur J Pharm Biopharm: Official Journal of Arbeitsgemeinschaft fur Pharmazeutische Verfahrenstechnik eV. 2019;141:130-8. https://doi.org/10.1016/j.ejpb.2019.05.020.

5. García-Arieta A. Interactions between active pharmaceutical ingredients and excipients affecting bioavailability: impact on bioequivalence. Eur J Pharm Sci. 2014;65:89-97. https://doi.org/ 10.1016/j.ejps.2014.09.004.

6. Chen ML, Straughn AB, Sadrieh N, Meyer M, Faustino PJ, Ciavarella AB, Meibohm B, Yates CR, Hussain AS. A modern view of excipient effects on bioequivalence: case study of sorbitol. Pharm Res. 2007;24(1):73-80. https://doi.org/10.1007/ s11095-006-9120-4.

7. Fassihi AR, Dowse R, Robertson SSD. Influence of sorbitol solution on the bioavailability of theophylline. Int J Pharm. 1991;72(2):175-8. https://doi.org/10.1016/0378-5173(91)90056-T.

8. Shesky P, Sackett G, Maher L, Lentz KA, Tolle S, Polli JE. Roll compaction granulation of a controlled-release matrix tablet containing HPMC: effect of process scale-up on robustness of tablets and predicted in vivo performance. Pharm Tech. 1999;23(suppl):6-21.

9. Vaithianathan S, Haidar SH, Zhang X, Jiang W, Avon C, Dowling TC, Shao C, Kane M, Hoag SW, Flasar MH, Ting TY, Polli JE. Effect of common excipients on the oral drug absorption of Biopharmaceutics Classification System class 3 Drugs cimetidine and acyclovir. J Pharm Sci. 2016;105(2):9961005. https://doi.org/10.1002/jps.24643.

10. European Medicines Agency (EMA). Committee for Medicinal Products for Human Use (CHMP), EMA/CHMP/ICH/493213/ 2018. ICH M9 guideline on biopharmaceutics classification system-based biowaivers (Step 5). 2020. https:// www.ema.europa.eu/en/documents/scientificguideline/ich-m9biopharmaceutics-classification-system-based-biowaivers-step5 en.pdf. Accessed 02 Oct 2021.

11. Food and Drug Administration (FDA). Guidance for industry: M9 Biopharmaceutics Classification System-Based Biowaivers. Center for Drug Evaluation and Research (CDER), Center for Biologics Evaluation and Research (CBER);May 2021.

12. Cook JA, Davit BM, Polli JE. Impact of Biopharmaceutics Classification System-based biowaivers. Mol Pharm. 2010;7(5):1539-44. https://doi.org/10.1021/mp1001747.

13. Polli JE. In vitro studies are sometimes better than conventional human pharmacokinetic in vivo studies in assessing bioequivalence of immediate-release solid oral dosage forms. AAPS J. 2008;10(2):289-99.

14. Shah VP, Amidon GL. G.L. Amidon, H. Lennernas, V.P. Shah, and J.R. Crison. A theoretical basis for a biopharmaceutic drug classification: the correlation of in vitro drug product dissolution and in vivo bioavailability, Pharm Res 12, 413-420, 1995-Backstory of BCS. AAPS J. 2014;16(5):894-8. https:// doi.org/10.1208/s12248-014-9620-9.

15. Food and Drug Administration (FDA). Guidance for industry: waiver of in vivo bioavailability and bioequivalence studies for immediate-release solid oral dosage forms based on a biopharmaceutics classification system. Center for Drug Evaluation and Research (CDER);December 2017.
16. European Medicines Agency (EMA). Committee for Medicinal Products for Human Use (CHMP), CPMP/EWP/QWP/1401/98 Rev. 1/ Corr **. Guideline on the investigation of bioequivalence. 2010. https://www.ema.europa.eu/en/documents/scientificguideline/guidelineinvestigation-bioequivalence-rev1_en.pdf. Accessed 02 Oct 2021.

17. Davit BM, Kanfer I, Tsang YC, Cardot JM. BCS Biowaivers: similarities and differences among EMA, FDA, and WHO requirements. AAPS J. 2016;18(3):612-8. https://doi.org/ 10.1208/s12248-016-9877-2.

18. Metry M, Shu Y, Abrahamsson B, Cristofoletti R, Dressman JB, Groot DW, Parr A, Langguth P, Shah VP, Tajiri T, Mehta MU, Polli JE. Biowaiver monographs for immediate release solid oral dosage forms: metformin hydrochloride. J Pharm Sci. 2021;110(4):1513-26. https://doi.org/10.1016/j.xphs.2021.01.011.

19. Charoo NA, Abdallah DB, Bakheit AA, Haque KU, Hassan HA, Abrahamsson B, et al. Biowaiver monograph for immediate-release solid oral dosage forms: sitagliptin phosphate monohydrate. J Pharm Sci. 2021(1520-6017 (Electronic)); https://doi.org/10.1016/j.xphs.2021.09.031.

20. Charoo NA, Abdallah DB, Parveen T, Abrahamsson B, Cristofoletti R, Groot DW, Langguth P, Parr A, Polli JE, Mehta M, Shah VP, Tajiri T, Dressman J. Biowaiver monograph for immediate-release solid oral dosage forms: moxifloxacin hydrochloride. J Pharm Sci. 2020;109(9):2654-75. https://doi.org/ 10.1016/j.xphs.2020.06.007.

21. García MA, Cristofoletti R, Abrahamsson B, Groot DW, Parr A, Polli JE, et al. Biowaiver monograph for immediate-release solid oral dosage forms: carbamazepine. J Pharm Sci. 2021;110(5):1935-1947. https://doi.org/10.1016/ j.xphs.2021.02.019.

22. Rescigno A. Bioequivalence. Pharm Res. 1992;9(7):925-8. https://doi.org/10.1023/a:1015809201503.

23. Bois FY, Fau TT, Fau HW, Fau CM, Fau PR, Williams RL. Bioequivalence: performance of several measures of rate of absorption. Pharm Res. 1994;11(7):966-74. https://doi.org/ 10.1023/a:1018970901116.

24. Polli JE. Rekhi Gs, Augsburger LL, Shah VP. Methods to compare dissolution profiles and a rationale for wide dissolution specifications for metoprolol tartrate tablets. J Pharm Sci. 1997;86(6):690-700. https://doi.org/10.1021/js960473x.

25. Chinchilli VM, Elswick RK Jr. The multivariate assessment of bioequivalence. J Biopharm Stat. 1997;7(1):113-23. https:// doi.org/10.1080/10543409708835173.

26. Bois FY, Fau TT, Hauck WW, Chen ML, Patnaik R, Williams RL. Bioequivalence: performance of several measures of extent of absorption. Pharm Res. 1994;11(5):715-22.

27. Endrenyi L, Fau FS, Yan W. Cmax/AUC is a clearer measure than Cmax for absorption rates in investigations of bioequivalence. Int J Clin Pharmacol Ther Toxicol. 1991;29(10):394-9.

28. Marston SA, Polli JE. Evaluation of direct curve comparison metrics applied to pharmacokinetic profiles and relative bioavailability and bioequivalence. Pharm Res. 1997;14(10):1363-9.

29. Chen ML, Lesko L, Williams RL. Measures of exposure versus measures of rate and extent of absorption. Clin Pharmacokinet. 2001;40(8):565-72.

30. Cristofoletti R, Chiann C, Dressman JB, Storpirtis S. A comparative analysis of biopharmaceutics classification system and biopharmaceutics drug disposition classification system: a cross-sectional survey with 500 bioequivalence studies. J Pharm Sci. 2013;102(9):3136-44.

31. Food and Drug Administration Center for Drug Evaluation and Research. Guidance for industry: using the Inactive Ingredient Database. 2019. https://www.fda.gov/media/128687/download. Accessed 02 Oct 2021.

32. Lenhart A, Chey WD. A systematic review of the effects of polyols on gastrointestinal health and irritable bowel syndrome. Adv Nutr. 2017;8(4):587-96. https://doi.org/10.3945/ an.117.015560.

33. Adkin DA, Davis SS, Sparrow RA, Huckle PD, Phillips AJ, Wilding IR. The effects of pharmaceutical excipients on small intestinal transit. Br J Clin Pharmacol. 1995;39(4):381-7. https:// doi.org/10.1111/j.1365-2125.1995.tb04466.x.

34. Yamane M, Matsui K, Sugihara M, Tokunaga Y. The provisional no-effect threshold of sugar alcohols on oral drug absorption 
estimated by physiologically based biopharmaceutics model. J Pharm Sci. 2021;110(1):467-77. https://doi.org/10.1016/ j.xphs.2020.05.013.

35. Adkin DA, Davis SS, Sparrow RA, Huckle PD, Wilding IR. The effect of mannitol on the oral bioavailability of cimetidine. J Pharm Sci. 1995;84(12):1405-9. https://doi.org/10.1002/ jps.2600841205.

36. Adkison K, Wolstenholme A, Lou Y, Zhang Z, Eld A, Perger T, Vangerow H, Hayward K, Shaefer M, McCoig C. Effect of sorbitol on the pharmacokinetic profile of lamivudine oral solution in adults: an open-label, randomized study. Clin Pharmacol Ther. 2018;103(3):402-8. https://doi.org/10.1002/ cpt.943.

37. Strauch S, Jantratid E, Dressman JB, Junginger HE, Kopp S, Midha KK, Shah VP, Stavchansky S, Barends DM. Biowaiver monographs for immediate release solid oral dosage forms: lamivudine. J Pharm Sci. 2011;100(6):2054-63. https://doi.org/ 10.1002/jps.22449.

38. Sv O, Relleke M, Piniella PM. Lack of bioequivalence between generic risperidone oral solution and originator risperidone tablets. Int J Clin Pharmacol Ther. 2007;45(5 (Print)):293-9.

39. Sjogren E, Abrahamsson B, Augustijns P, Becker D, Bolger $\mathrm{MB}$, Brewster $\mathrm{M}$, et al. In vivo methods for drug absorption comparative physiologies, model selection, correlations with in vitro methods (IVIVC), and applications for formulation/ API/excipient characterization including food effects. Eur J Pharm Sci. 2014;57:99-151. https://doi.org/10.1016/ j.ejps.2014.02.010.

40. Parr A, Hidalgo IJ, Bode C, Brown W, Yazdanian M, Gonzalez MA, Sagawa K, Miller K, Jiang W, Stippler ES. The effect of excipients on the permeability of BCS class III compounds and implications for biowaivers. Pharm Res. 2016;33(1):167-76. https://doi.org/10.1007/s11095-015-1773-4.

41. Gurjar RA-O, Chan CYS, Curley P, Sharp J, Chiong J, Rannard $\mathrm{S}$, et al. Inhibitory effects of commonly used excipients on Pglycoprotein in vitro. Mol Pharm. 2018;15(11):4835-42.

42. Cornaire G, Woodley J, Hermann P, Cloarec A, Arellano C, Houin G. Impact of excipients on the absorption of Pglycoprotein substrates in vitro and in vivo. Int J Pharm. 2004;278(1):119-31. https://doi.org/10.1016/ j.ijpharm.2004.03.001.

43. Food and Drug Administration Center for Drug Evaluation and Research. Guidance for industry: scale-up and postapproval changes - immediate release solid oral dosage forms (SUPACIR). 1995. https://www.fda.gov/media/70949/download. Accessed 02 Oct 2021.

44. Gupta E, Barends DM, Yamashita E, Lentz KA, Harmsze AM, Shah VP, Dressman JB, Lipper RA. Review of global regulations concerning biowaivers for immediate release solid oral dosage forms. Eur J Pharm Sci. 2006;29(3-4):315-24. https:// doi.org/10.1016/j.ejps.2006.05.001.

45. Food and Drug Administration Center for Drug Evaluation and Research. Guidance for industry: submission of summary bioequivalence data for ANDAs. 2011. https://www.fda.gov/ media/75535/download. Accessed 02 Oct 2021.

46. Plöger GF, Quizon PM, Abrahamsson B, Cristofoletti R, Groot DW, Parr A, Langguth P, Polli JE, Shah VP, Tajiri T, Mehta MU, Dressman J. Biowaiver monographs for immediate release solid oral dosage forms: cephalexin monohydrate. J Pharm Sci. 2020;109(6):1846-62. https://doi.org/10.1016/j.xphs.2020.03.025.

47. Midha KK, Hubbard JW, Rawson M, Gavalas L. The application of partial areas in assessment of rate and extent of absorption in bioequivalence studies of conventional release products: experimental evidence. Eur J Pharm Sci. 1994;2(5):351-63. https://doi.org/10.1016/0928-0987(94)00062-X.

48. Otter M, Oswald S, Siegmund W, Keiser M. Effects of frequently used pharmaceutical excipients on the organic cation transporters 1-3 and peptide transporters $1 / 2$ stably expressed in MDCKII cells. Eur J Pharm Biopharm: Official Journal of Arbeitsgemeinschaft fur Pharmazeutische Verfahrenstechnik eV. 2017;112:187-95. https://doi.org/10.1016/j.ejpb.2016.11.028.

49. Ashford M. Bioavailability - physicochemical and dosage form factors. In: Aulton ME, Taylor KMG, editors. Aulton's pharmaceutics: the design and manufacture of medicines. Netherlands: Elsevier; 2018. p. 319-338.
50. Chen M-L, Sadrieh N, Yu L. Impact of osmotically active excipients on bioavailability and bioequivalence of BCS class III drugs. AAPS J. 2013;15(4):1043-50. https://doi.org/10.1208/ s12248-013-9509-z.

51. Yang B, Smith DE. Significance of peptide transporter 1 in the intestinal permeability of valacyclovir in wild-type and PepT1 knockout mice. Drug Metab Dispos. 2013;41(3):608-14. https:// doi.org/10.1124/dmd.112.049239.

52. Ganapathy ME, Huang W, Wang H, Ganapathy V, Leibach FH. Valacyclovir: a substrate for the intestinal and renal peptide transporters PEPT1 and PEPT2. Biochem Biophys Res Commun. 1998;246(2):470-5. https://doi.org/10.1006/ bbrc. 1998.8628 .

53. Zhang W, Li Y, Zou P, Wu M, Zhang Z, Zhang T. The effects of pharmaceutical excipients on gastrointestinal tract metabolic enzymes and transporters-an Update. AAPS J. 2016;18(4):830 43. https://doi.org/10.1208/s12248-016-9928-8.

54. Rege BD, Yu LX, Hussain AS, Polli JE. Effect of common excipients on Caco-2 transport of low-permeability drugs. J Pharm Sci. 2001;90(11):1776-86. https://doi.org/10.1002/jps.1127.

55. Rege BD, Kao JP, Polli JE. Effects of nonionic surfactants on membrane transporters in Caco-2 cell monolayers. Eur J Pharm Sci. 2002;16(4-5):237-46. https://doi.org/10.1016/s09280987(02)00055-6.

56. Dahan A, Amidon GL. Segmental dependent transport of low permeability compounds along the small intestine due to Pglycoprotein: the role of efflux transport in the oral absorption of BCS class III drugs. Mol Pharm. 2009;6(1):19-28. https:// doi.org/10.1021/mp800088f.

57. Bajaj R, Chong LB, Zou L, Tsakalozou E, Ni Z, Giacomini KM, et al. In vitro evaluation of excipients as inhibitors of human intestinal P-glycoprotein. The FASEB Journal. 2019;33(S1) $814.3-.3$ h t t p s:// d o i.org / $10.1096 /$ fasebj.2019.33.1_supplement.814.3.

58. Dintaman JM, Silverman JA. Inhibition of P-glycoprotein by Dalpha-tocopheryl polyethylene glycol 1000 succinate (TPGS). Pharm Res. 1999;16(10):1550-6. https://doi.org/10.1023/ a:1015000503629.

59. Bogman K, Erne-Brand F, Alsenz J, Drewe J. The role of surfactants in the reversal of active transport mediated by multidrug resistance proteins. J Pharm Sci. 2003;92(6):1250-61. https://doi.org/10.1002/jps.10395.

60. Bittner B, Guenzi A, Fullhardt P, Zuercher G, Gonzalez RC, Mountfield RJ. Improvement of the bioavailability of colchicine in rats by co-administration of D-alpha-tocopherol polyethylene glycol 1000 succinate and a polyethoxylated derivative of 12 hydroxy-stearic acid. Arzneimittelforschung. 2002;52(9):684-8. https://doi.org/10.1055/s-0031-1299951.

61. Anderle P, Niederer E, Rubas W, Hilgendorf C, SpahnLangguth H, Wunderli-Allenspach H, Merkle HP, Langguth P. P-Glycoprotein (P-gp) mediated efflux in Caco-2 cell monolayers: the influence of culturing conditions and drug exposure on P-gp expression levels. J Pharm Sci. 1998;87(6):757-62. https:// doi.org/10.1021/js970372e.

62. Collett A, Higgs NB, Sims E, Rowland M, Warhurst G. Modulation of the permeability of $\mathrm{H} 2$ receptor antagonists cimetidine and ranitidine by $\mathrm{P}$-glycoprotein in rat intestine and the human colonic cell line Caco-2. J Pharmacol Exp Ther. 1999;288(1):171-8.

63. Twarog C, Fattah S, Heade J, Maher S, Fattal E, Brayden DJ. Intestinal permeation enhancers for oral delivery of macromolecules: a comparison between salcaprozate sodium (SNAC) and sodium caprate (C10). Pharmaceutics. 2019;11(2):78. https:// doi.org/10.3390/pharmaceutics11020078.

64. Cao X, Gibbs ST, Fang L, Miller HA, Landowski CP, Shin HC, Lennernas H, Zhong Y, Amidon GL, Yu LX, Sun D. Why is it challenging to predict intestinal drug absorption and oral bioavailability in human using rat model. Pharm Res. 2006;23(8):1675-86. https://doi.org/10.1007/s11095-006-9041-2.

65. Birch D, Diedrichsen RG, Christophersen PC, Mu H, Nielsen HM. Evaluation of drug permeation under fed state conditions using mucus-covered Caco-2 cell epithelium. Eur J Pharm Sci. 2018;118:144-53. https://doi.org/10.1016/j.ejps.2018.02.032. 
66. Volpe DA. Variability in Caco-2 and MDCK cell-based intestinal permeability assays. J Pharm Sci. 2008;97(2):712-25. https://doi.org/10.1002/jps.21010.

67. Jin X, Luong TL, Reese N, Gaona H, Collazo-Velez V, Vuong C, Potter B, Sousa JC, Olmeda R, Li Q, Xie L, Zhang J, Zhang P, Reichard G, Melendez V, Marcsisin SR, Pybus BS. Comparison of MDCK-MDR1 and Caco-2 cell based permeability assays for anti-malarial drug screening and drug investigations. J Pharmacol Toxicol Methods. 2014;70(2):188-94. https:// doi.org/10.1016/j.vascn.2014.08.002.

68. Avdeef A, Tam KY. How well can the Caco-2/Madin-Darby canine kidney models predict effective human jejunal permeability? J Med Chem. 2010;53(9):3566-84.

69. Wikman A, Karlsson J, Carlstedt I, Artursson P. A drug absorption model based on the mucus layer producing human intestinal goblet cell line HT29-H. Pharm Res. 1993;10(6):84352. https://doi.org/10.1023/a:1018905109971.

70. Behrens I, Stenberg P, Artursson P, Kissel T. Transport of lipophilic drug molecules in a new mucus-secreting cell culture model based on HT29-MTX cells. Pharm Res. 2001;18(8):113845. https://doi.org/10.1023/a:1010974909998.

71. Kleiveland CR. Co-cultivation of Caco-2 and HT-29MTX. In: Verhoeckx K, Cotter P, Lopez-Exposito I, Kleiveland C, Lea T, Mackie A, et al., editors. The impact of food bioactives on health: in vitro and ex vivo models. Cham $(\mathrm{CH})$ : Springer International Publishing; 2015. p. 135-40.

72. Hilgendorf C, Spahn-Langguth H, Regardh CG, Lipka E, Amidon GL, Langguth P. Caco-2 versus Caco-2/HT29-MTX co-cultured cell lines: permeabilities via diffusion, inside- and outside-directed carrier-mediated transport. J Pharm Sci. 2000;89(1):63-75. https://doi.org/10.1002/(SICI)15206017(200001)89:1<63::AID-JPS7>3.0.CO;2-6.

73. Lozoya-Agullo I, Araújo F, González-Álvarez I, MerinoSanjuán M, González-Álvarez M, Bermejo M, Sarmento B. Usefulness of Caco-2/HT29-MTX and Caco-2/HT29-MTX/Raji $\mathrm{B}$ coculture models to predict intestinal and colonic permeability compared to Caco-2 monoculture. Mol Pharm. 2017;14(4):1264-70.

74. Darling NJ, Mobbs CL, González-Hau AL, Freer M, Przyborski S. Bioengineering novel in vitro co-culture models that represent the human intestinal mucosa with improved Caco-2 structure and barrier function. Front Bioeng Biotechnol. 2020;8:992.

75. Dahlgren DA-O, Lennernäs H. Intestinal permeability and drug absorption: predictive experimental, computational and in vivo approaches. Pharmaceutics. 2019;11(8):411.

76. Food and Drug Administration (FDA). Guidance for industry: in vitro drug interaction studies - cytochrome P450 enzyme- and transporter-mediated drug interactions. Center for Drug Evaluation and Research (CDER); January 2020.

77. Food and Drug Administration (FDA). Guidance for industry: clinical drug interaction studies - cytochrome P450 enzymeand transporter-mediated drug interactions. Center for Drug Evaluation and Research (CDER); January 2020.

78. Food and Drug Administration (FDA). Drug Development and Drug Interactions: Table of Substrates, Inhibitors and Inducers. 2020. https://www.fda.gov/drugs/drug-interactions-labeling/drugdevelopment-and-drug-interactions-table-substrates-inhibitorsand-inducers Accessed 02 Oct 2021.

79. Lentz KA, Polli JW, Wring SA, Humphreys JE, Polli JE. Influence of passive permeability on apparent P-glycoprotein kinetics. Pharm Res. 2000;17(12):1456-60. https://doi.org/ 10.1023/a:1007692622216.

80. Jantratid E, Prakongpan S, Dressman JB, Amidon GL, Junginger HE, Midha KK, Barends DM. Biowaiver monographs for immediate release solid oral dosage forms: cimetidine. J Pharm Sci. 2006;95(5):974-84. https://doi.org/10.1002/ jps.20614.

81. Trueck C, Hsin CH, Scherf-Clavel O, Schaeffeler E, Lenssen R, Gazzaz M, Gersie M, Taubert M, Quasdorff M, Schwab M, Kinzig M, Sörgel F, Stoffel MS, Fuhr U. A clinical drug-drug interaction study assessing a novel drug transporter phenotyping cocktail with adefovir, sitagliptin, metformin, pitavastatin, and digoxin. Clin Pharmacol Ther. 2019;106(6):1398-407. https:// doi.org/10.1002/cpt.1564.

82. Nader AM, Foster DR. Suitability of digoxin as a Pglycoprotein probe: implications of other transporters on sensitivity and specificity. J Clin Pharmacol. 2014;54(1):3-13.

83. LANOXIN [package insert]. Concordia Pharmaceuticals, Inc.; 2015.

84. Caldeira TG, Ruiz-Picazo A, Lozoya-Agullo I, SaudeGuimaraes DA, Gonzalez-Alvarez M, de Souza J, et al. Determination of intestinal permeability using in situ perfusion model in rats: Challenges and advantages to BCS classification applied to digoxin. Int J Pharm. 2018;551(1-2):148-57. https:// doi.org/10.1016/j.ijpharm.2018.09.022.

85. Chu X, Liao M, Shen H, Yoshida K, Zur AA, Arya V, Galetin A, Giacomini KM, Hanna I, Kusuhara H, Lai Y, Rodrigues D, Sugiyama Y, Zamek-Gliszczynski MJ, Zhang L, on behalf of the International Transporter Consortium. Clinical probes and endogenous biomarkers as substrates for transporter drug-drug interaction evaluation: perspectives from the International Transporter Consortium. Clin Pharmacol Ther. 2018;104(5):836-64. https://doi.org/10.1002/cpt.1216.

Publisher's Note Springer Nature remains neutral with regard to jurisdictional claims in published maps and institutional affiliations. 